02

\title{
Теоретико-групповая интерпретация спектров гигантского комбинационного рассеяния фталоцианина меди, адсорбированного на фосфиде галлия
}

\author{
(C) А.М. Полуботко 1 , В.П. Челибанов ${ }^{2}$ \\ ${ }^{1}$ Физико-технический институт им. А.Ф. Иофрфе РАН, \\ 194021 Санкт-Петербург, Россия \\ ${ }^{2}$ Университет ИТМО, \\ 197101 Санкт Петербург, Россия \\ e-mail: Chelibanov@gmail.com
}

Поступила в редакцию 19.05.2018 г.

В окончательной редакции 20.06.2018 г.

Принята к публикации 06.11.2018 г.

\begin{abstract}
Исследованы спектры гигантского комбинационного рассеяния молекулы фталоцианина меди, адсорбированной на подложке из GaP. Показано, что в спектре появляются очень сильные линии, запрещенные в обычном комбинационном рассеянии. Анализ спектров указывает, что эти линии обусловлены возникновением в системе сильного квадрупольного взаимодействия, а также большим усилением тангенциальных компонент напряженности электрического поля. Как было показано ранее, последний эффект характерен для гигантского комбинационного рассеяния на полупроводниковых и диэлектрических подложках, где усиливается не только нормальная, но и тангенциальные компоненты напряженности поля на поверхности.
\end{abstract}

DOI: $10.21883 /$ OS.2019.03.47363.143-18

Исследование гигантского комбинационного рассеяния (Гиг.КР) на полупроводниковых и диэлектрических подложках представляет большой интерес как с теоретической, так и с экспериментальной точек зрения. В [1] показано, что причиной Гиг.КР в этом случае, так же как и в случае металлических подложек, является поверхностная шероховатость. Причем усиление происходит в малых областях поверхности с большой положительной кривизной. Нами было показано, что в случае Гиг.КР на полупроводниках и диэлектриках усиление в этих областях меньше, чем на металле с таким же значением модуля диэлектрической проницаемости. Этот результат связан с тем, что диэлектрики и полупроводники в принципе прозрачны для электромагнитного поля в достаточно широкой области частот в отличие от металла, который стремится „вытолкнуть“ поле. Поэтому системы с полупроводниковыми или диэлектрическими подложками в отличие от металлов имеют „меньшую неоднородность“ среды, что приводит к меньшему усилению поля и его производных. Однако в соответствии с экспериментальными и теоретическими результатами [1] на шероховатых поверхностях полупроводников и диэлектриков должно происходить усиление как нормальной, так и тангенциальной компонент, что приводит к определенным особенностям в спектрах Гиг. КР. Нами была проведена интерпретация теоретико-групповыми методами спектров [2] Гиг.КР молекулы фталоцианина меди (рис. 1), адсорбированной на фосфиде галлия GaP. Как известно, молекула фталоцианина меди относится к группе симметрии $D_{1 h}$.
Спектры этой молекулы, адсорбированной на частицах $\mathrm{GaP}$ со средним размером $d=106,60,40 \mathrm{~nm}$ в интервале волновых чисел $500-1700 \mathrm{~cm}^{-1}$ показаны на рис. 2. Сразу отметим, что символ $* 2$ около кривой 1 означает, что интенсивность всего спектра должна быть умножена на 2. Также отметим, что спектры снимались при длине волны падающего излучения $514.5 \mathrm{~nm}$. При этом коэффициент усиления составил примерно 700, 300 и 200 соответственно для частиц со средними размерами $d=106,60$, и $40 \mathrm{~nm}$. По нашим представлениям фта-

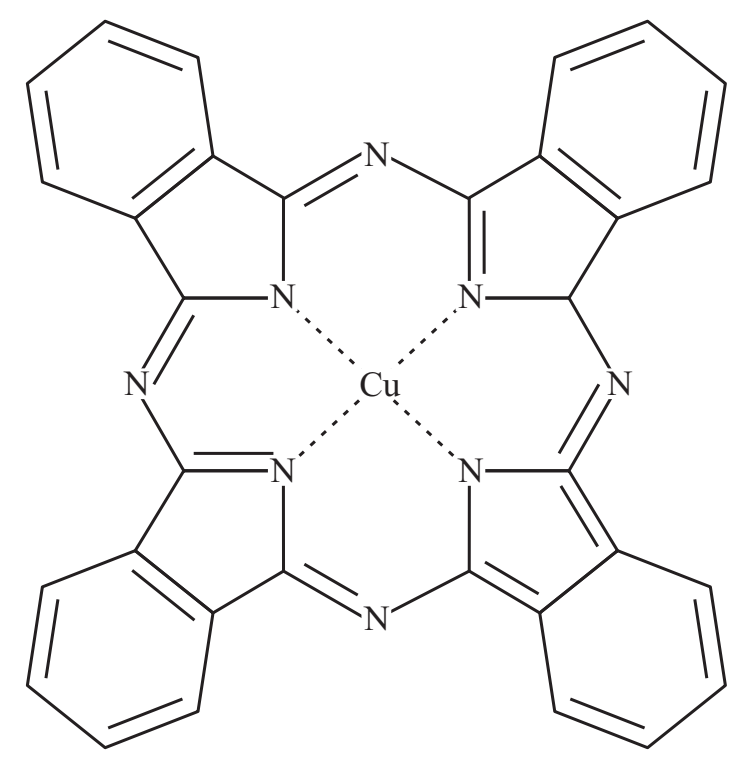

Рис. 1. Молекула фталоцианина меди. 


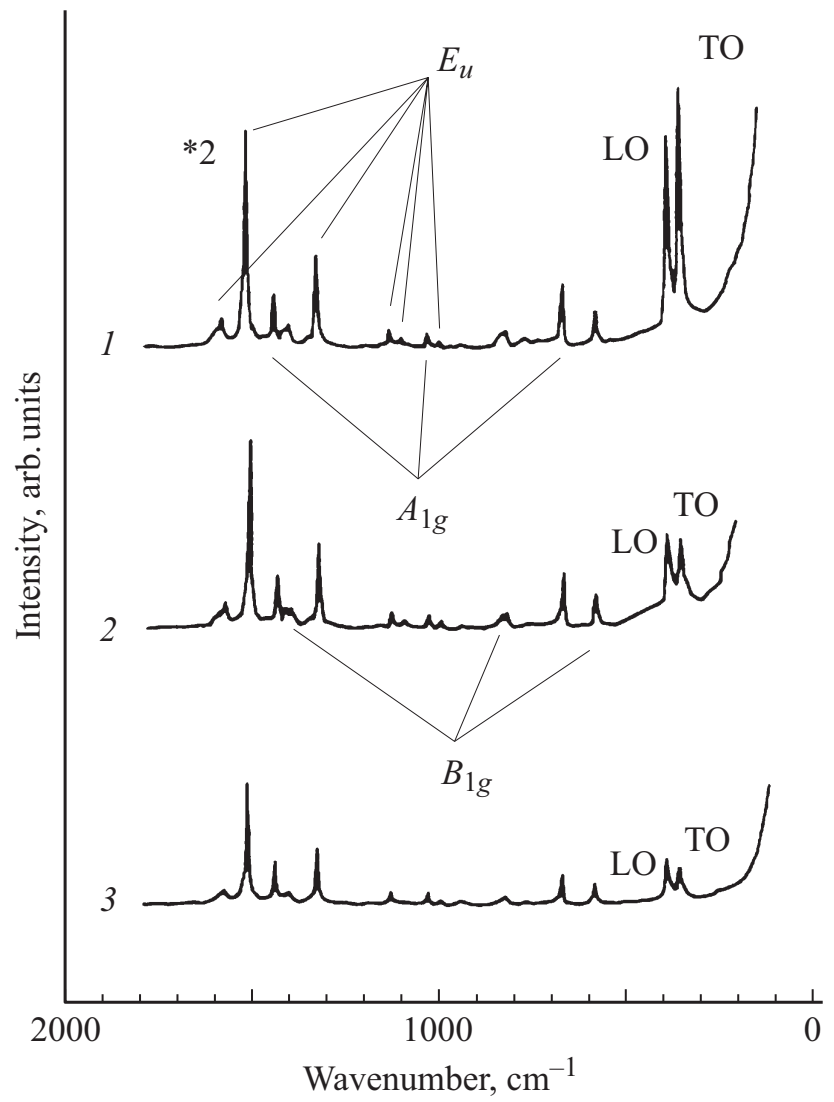

Pис. 2. Спектры фталоцианина меди, адсорбированного на подложке фосфида галлия: 1 - средний размер частиц $106 \mathrm{~nm}$, коэффициент усиления 700; 2 - средний размер частиц $60 \mathrm{~nm}$, коэффициент усиления 300; 3 - средний размер частиц $40 \mathrm{~nm}$, коэффициент усиления 200. LO, ТО-линии отвечают соответственно продольным и поперечным фононам подложки. Символ $* 2$ у кривой 1 означает, что интенсивность всего спектра должна быть умножена на 2.

лоцианин меди адсорбируется параллельно поверхности наночастиц. Из таблицы, составленной по результатам работы [3], видно, что в спектре присутствуют достаточно интенсивные линии, обусловленные колебаниями с неприводимыми представлениями $A_{1 g}$ и $B_{1 g}$, с волновыми числами соответственно $680,1030,1440 \mathrm{~cm}^{-1}$ и $580,1030,1400 \mathrm{~cm}^{-1}$, характерные для обычного рамановского рассеяния. Однако в системе появляются и запрещенные линии с волновыми числами 1000 , 1096, 1121, 1327, 1511, $1580 \mathrm{~cm}^{-1}$ и неприводимым представлением $E_{u}$, обусловленные колебаниями, преобразующимися как компоненты дипольного момента $\left(d_{x}, d_{y}\right)$, а также очень слабая линия с волновым числом $950 \mathrm{~cm}^{-1}$ и неприводимым представлением $A_{2 u}$, обусловленная колебанием, преобразующимся как дипольный момент $d_{z}$, перпендикулярный поверхности. Появление запрещенных линий с неприводимым представлением $E_{u}$ согласуется с теорией Гиг. КР на полупроводниковых и диэлектрических подложках [1], по которой на них происходит усиление не только нормальной, но и тан-
Соотнесение линий фталоцианина меди, адсорбированного на $\mathrm{GaP}$ [3], неприводимым представлениям группы $D_{4 h}$

\begin{tabular}{l|c}
\hline Волновое число, $\mathrm{cm}^{-1}$ & Соотнесение \\
\hline 580 ср. & $B_{1 g}$ \\
680 ср. & $A_{1 g}$ \\
830 оч. сл. & $B_{1 g}$ \\
950 оч. сл. & $A_{2 u}$ \\
1000 оч. сл. & $E_{u}$ \\
1030 оч. сл. & $A_{1 g}$ \\
1096 оч. сл. & $E_{u}$ \\
1121 оч. сл. & $E_{u}$ \\
1327 с. & $E_{u}$ \\
1400 оч. сл. & $B_{1 g}$ \\
1440 ср. & $A_{1 g}$ \\
1511 с. & $E_{u}$ \\
1580 сл. & $E_{u}$
\end{tabular}

Примечание. оч. сл. - очень слабая, сл. - слабая, ср. - средняя, с - сильная.

генциальной компонент электрического поля. Согласно теории Гиг.КР [4] рассеяние может происходить через дипольные и квадрупольные моменты $d_{x}, d_{y}, d_{z}, Q_{x x}$, $Q_{y y}, Q_{z z}$ или в симметричных молекулах через дипольные моменты и линейные комбинации вышеуказанных квадрупольных моментов, преобразующиеся по единичному неприводимому представлению. Для молекулы фталоцианина меди это $Q_{1}=Q_{x x}+Q_{y y}$ и $Q_{2}=Q_{z z}$, которые называются основными квадрупольными моментами $Q_{\text {main. }}$ Здесь мы не будем повторять наши работы, в частности, монографию [4]. Укажем только, что рассеяние через основные квадрупольные моменты $Q_{1}, Q_{2}$ и дипольные моменты, обозначенные как $\left(d-Q_{\text {main }}\right)$, определяет появление запрещенных линий. Поэтому их появление, а также появление очень слабой линии с неприводимым представлением $A_{2 u}$ говорит о возникновении достаточно сильного квадрупольного взаимодействия, которое возникает в данном случае в системе с полупроводниковой подложкой. Отметим, что мы уже указывали на появление запрещенных линий на молекуле гидрохинона, адсорбированной на подложке из $\mathrm{TiO}_{2}$ [5], однако здесь запрещенные линии с неприводимым представлением имеют интенсивность даже большую, чем разрешенные линии с неприводимыми представлениями $A_{1 g}$ и $B_{1 g}-$ в отличие от гидрохинона, адсорбированного на $\mathrm{TiO}_{2}$, где они были очень слабы. Одной из причин может быть тот факт, что молекула фталоцианина меди значительно больше молекулы гидрохинона, а квадрупольное взаимодействие растет с увеличением размера молекул.

\section{Список литературы}

[1] Полуботко А.М., Челибанов В.П. // Опт. и спектр. 2017. T. 122. № 6. C. 980. 
[2] Hayashi S., Koh R., Ichiyama Y., Yamamoto K. // Phys. Rev. Lett. 1988. V. 60. N 11. P. 1085.

[3] Harbeck S., Mack H.-G. Электронный pecypc.

Режим доступа. https://publikationen.uni-tuebingen.de/xmlui/ bitstream/handle/10900/49961/pdf/

CuPc_TiOPc_IR_Raman_Okt2013.pdf?sequence $=1 \&$

isAllowed $=\mathrm{y}$

[4] Polubotko A.M. The Dipole Quadrupole Theory of Surface Enhanced / Raman Scattering. N. Y.: Nova Sci. Publ. Inc., 2009.

[5] Полуботко А.М., Челибанов В.П. // Опт. и спектр. 2018. T. 124. № 1. C. 68. 